\title{
ОСОБЕННОСТИ ИСПОЛЬЗОВАНИЯ ТЕХНОЛОГИИ ДОПОЛНЕННОЙ РЕАЛЬНОСТИ В ОБРАЗОВАТЕЛЬНОМ ПРОЦЕССЕ
}

\section{FEATURES OF USING AUGMENTED REALITY TECHNOLOGY IN THE EDUCATIONAL PROCESS \\ O. Mnatsakanyan}

Summary: The article deals with the application of innovative technologies in the educational process. The main directions of using augmented reality technology in the educational sphere are given, and the characteristics of this technology are described. There are examples of software products and platforms that can be used in the educational process.

Keywords: innovative technologies, augmented reality, educational process, competence.
$\mathrm{O}$ дной из главных задач на сегодня является обеспечение современного качества образования, которое должно соответствовать актуальным и перспективным потребностям личности, а также общества и государства. Высшие образовательные учреждения являются основной составляющей профессиональной деятельности будущих специалистов. Современные информационные технологии, являясь мощным инструментом для наглядного представления учебной информации, предоставляют новые перспективы и возможности для повышения эффективности образовательного процесса. Использование инновационных технологий в образовании является важным и современным подходом к образовательному процессу, который значительно повышает качество самого процесса для достижения образовательных целей.

Формируя высокий уровень обучающихся с помощью инновационных технологий в информационном пространстве, происходит развитие предметных знаний и умений, а также высокий уровень профессиональной компетентности [4]. Применяя в обучении инновационные технологии, у студентов формируются различные умения, такие как организация, планирование, оценка и корректировка своей учебной деятельности.

В настоящее время современные специалисты должны иметь представление о содержании и структуре виртуальной предметной среды, использовать цифровые информационные ресурсы в образовательном процессе
[3]. Насколько глубоко происходит интеграция современных технологий в настоящее время, настолько эффективно происходит повышение учебного процесса.

Одним из наиболее быстро развивающихся разделов современных информационных технологий является трехмерная графика, а также виртуальная и дополненная реальность.

В образовании построение компьютерных моделей из различных предметных областей дает возможность педагогам и обучающимся использовать технологии будущего, показывать в динамике изучаемый материал. Технология дополненной реальности может быть использована:

- в качестве симуляторов (позволяющих проводить практические, лабораторные работы);

- для демонстрации процессов, явлений и объектов (показать которые в реальности затруднительно или невозможно);

- как вспомогательные средства (для повышения наглядности и интерактивности изучаемого предмета) [1].

Дополненная реальность (augmentedreality, AR) - это технология, созданная на основе наложения каких-либо объектов или информации на события, происходящие в реальном времени. Данная технология, как показывают исследования, может являться настоящим прорывом в области образования. К основным направлениям в об- 
ласти использования технологии дополненной реальности в образовательной сфере можно отнести:

- игровые и обучающие приложения;

- виртуальные тренажеры и модели;

- специальные учебные издания;

Можно отметить такие преимущества и характеристики дополненной реальности, как:

- наглядность (возможность с помощью трехмерной графики увидеть различные процессы и явления);

- безопасность (независимо от изучаемого объекта или явления, отсутствует опасность для здороВья);

- интерактивность (более детально происходит взаимодействие с объектами).

- доступность (учебные материалы можно осваивать независимо от времени и места нахождения).

Технология дополненной реальности позволяет визуально воспроизводить процессы, которые очень сложно или практически невозможно воссоздавать способами и средствами реального мира, тем самым делая процесс обучения более понятным и увлекательным [5]. Можно также превратить статичные страницы учебника, плакаты или печатные руководства в выразительную анимацию или увлекательную игру.

Приведем примеры программных продуктов и платформ, которые можно использовать в образовательной сфере.

Платформа Unity считается одной из лучших в мире, имея надёжную экосистему, она работает под различными операционными системами. Unity используется для разработки двух и трехмерных приложений в реальном времени. Достаточно простой интерфейс редактора по- зволяет быстро и легко настраивать различные окна и производить отладку событий прямо в редакторе. Важным преимуществом платформы является межплатформенная поддержка, модульная система компонентов, а также визуальная среда разработки.

Следующий конструктор для создания проектов дополненной и виртуальной реальности EV Toolbox считается первым, созданным в России, программным продуктом. EV Toolbox имеет удобный графический интерфейс с широким функционалом. Демонстрация проектов создается как на мобильных устройствах, так и на VR шлемах и AR очках. У конструктора EV Toolbox имеются готовые примеры и шаблоны проектов дополненной и виртуальной реальности, библиотека 3D моделей, обучающие материалы и системная поддержка [2].

Далее можно рассмотреть ARCore, разработанный Google, данный комплект предназначен для разработки программного обеспечения, позволяющий создавать приложения дополненной реальности. Используя три основные технологии (отслеживание движения, понимание окружающей среды, оценка освещённости) ARCore позволяет проводить интеграцию виртуального контента с реальным миром с помощью камеры смартфона.

Таким образом, использование технологии дополненной реальности можно представить как новый способ представления информации, который эффективно способствует освоению методических приемов в обучении, дополняя визуализацией учебный материал. Реалистичные трехмерные модели, виртуальные объекты во взаимодействии с дополненной реальностью позволяют повысить мотивацию к самообучению, потенциал, концентрацию внимания, обучающихся в образовательном процессе.

\section{ЛИТЕРАТУРА}

1. Елесин, С.С. Виртуальная реальность в образовании: сомнения и надежды / С.С. Елесин, А.В. Фещенко. // Гуманитарная информатика. - 2016. - №10. С. 109-114.

2. Иванилова И.В., Юркевич Е.В., Крюкова Л.Н. Механизмы использования технологий дополненной реальности в образовании. //Современное педагогическое образование. - 2020. - № 1. С. 84-89.

3. Мамалова Х.Э. Возможности дидактической компьютерной среды вуза как средство организации самостоятельной работы студентов. // Мир науки, культуры, образования. - 2018. - № 2 (69). С. 53-54.

4. Мнацаканян 0.Л. Формирование ключевых компетенций учащихся в сетевой проектной деятельности / 0.Л. Мнацаканян // Стандарты и мониторинг в образовании. - 2012. - №4. - С. 21-23.

5. Некрасова И. И. Дополненная реальность в образовании // Электронное обучение в непрерывном образовании 2019: сборник научных трудов VI Международной научно-практической конференции, посвященная памяти Александра Николаевича Афанасьева (Россия, Ульяновск, 20-21 мая 2019 г.) Ульяновск: УлГТУ, - 2019. - С. 346-349

(c) Мнацаканян Ольга Леонидовна (mnaolga@yandex.ru). 